\title{
Contrasting nuclear-plastidial phylogenetic patterns in the recently diverged Iberian Phlomis crinita and P. lychnitis lineages (Lamiaceae)
}

\author{
Rafael G. Albaladejo ${ }^{1}$, Javier Fuertes Aguilar ${ }^{2}$, Abelardo Aparicio' ${ }^{1}$ \& Gonzalo Nieto Feliner 2 \\ ${ }^{1}$ Departamento de Biología Vegetal y Ecología. Facultad de Farmacia, Universidad de Sevilla, E-41012 \\ Sevilla,Spain.albaladejo@us.es (authorfor correspondence); abelardo@us.es \\ ${ }^{2}$ Real Jardín Botánico (CSIC), Plaza de Murillo 2,E-28014 Madrid, Spain.jfuertes@ma-rjb.csic.es;nieto@ \\ ma-rjb.csic.es
}

\begin{abstract}
Systematic and evolutionary relationships within the diploid Western Mediterranean Phlomis crinita/lychnitis complex remain controversial apparently due to hybridization and introgression. This study examines patterns of sequence variation in the nuclear ribosomal DNA (ITS region) and three non-coding plastid DNA regions (trnH-psbA, trnT-trnL and $a t p B-r b c L)$ in this complex in an aim to clarify whether hybridization, introgression or lineage sorting resulting from recent diversification is mainly responsible for poorly understood relationships. Information recovered from nuclear and chloroplast markers was found to be strongly incongruent. Phylogenetic analysis of inferred nuclear ITS ribotypes is consistent with previous morphometric and taxonomic results in distinguishing two sister lineages, $P$. crinita s.l. and $P$. lychnitis. In addition, the high number of additive polymorphisms detected in ITS sequences suggests the sharing of ancestral variability and local patterns of gene flow within the complex. In contrast, the pattern of chloroplast haplotype variation is geographic rather than taxonomic, which might be caused by low mutation rates combined with frequent instances of interspecific hybridization. To integrate the apparently discordant plastid and nuclear evidence, we suggest that both lineage sorting and horizontal transfer have been involved. Even though pinpointing cases due to either phenomenon is difficult, the available data provide evidence of two sister lineages where hybridization events can be identified despite the inheritance of ancestral polymorphisms.
\end{abstract}

KEYWORDS: Hybridization, lineage sorting, non-coding plastid DNA, nuclear ribosomal ITS, Phlomis.

\section{INTRODUCTION}

Despite the amount of work published on phylogeography of European plant species in recent years, Mediterranean plant groups have been comparatively much less studied (but see Gutiérrez Larena \& al., 2002; Hampe \& al., 2004; and other papers in this volume). This is partly due to the difficulty of unravelling complex patterns in this area that resulted from a combination of causes such as Pleistocene glaciation cycles, the Messinian salinity crisis and the influence of anthropogenic factors. One of the outcomes was the diversity accumulated in these southern European regions.

Depending on the level of isolation and the degree of differentiation acquired by populations or species along successive contraction-expansion cycles, secondary contacts resulted either in overlapping distribution areas or in different amounts of hybridization or introgression (Hewitt, 2000). In the less favourable cases, untangling the genetic polymorphisms caused by a recent divergence process from those resulting from hybridization and introgression can be a challenging task.

Detection of interspecific gene flow has rapidly improved in recent decades following the availability of adequate and precise molecular markers, including nuclear and chloroplast DNA sequence data (Rieseberg \& Soltis, 1991; Rieseberg \& Wendel, 1993; Rieseberg \& al., 1996). The internal transcribed spacer (ITS) of nrDNA is one of the most widely used nuclear markers in phylogenetic studies below the family level (Baldwin \& al., 1995; Álvarez \& Wendel, 2003). The fact that intraindividual heterogeneity for ITS repeat copies can remain for a given period of time following a hybridization event despite the action of concerted evolution (Zimmer \& al., 1980) also makes this marker useful in detecting cases of reticulate evolution among divergent lineages (Sang \& al., 1995; Whittall \& al., 2000; Fuertes Aguilar \& Nieto Feliner, 2003). Even if concerted evolution has been active and different copies are homogenised, ITS sequence data may still provide valuable information on reticulate evolution when showing incongruent patterns with respect to other differently inherited markers (e.g., cpDNA, Rieseberg, 1991) or morphological and biogeographical evidence (Sytsma, 1990; Fuertes Aguilar \& al., 1999b; Nieto Feliner \& al., 2004).

The genus Phlomis L. (Lamiaceae) comprises over 
100 species with a main centre of diversification in the eastern Mediterranean basin (Azizian \& Moore, 1982) with hybrid taxa quite frequently reported in local floras (e.g., Huber-Morath, 1982; Dadandi \& Duman, 2003). However, to our knowledge hybridization in the genus has only been unambiguously confirmed with the use of molecular markers for $P$. ×margaritae Aparicio \& Silvestre ( $P$. crinita subsp. malacitana $\times P$. purpurea), an $\mathrm{F}_{1}$ hybrid with only one known population in southern Spain (Aparicio \& al., 2000). This might represent an example of hybridization between relatively distant lineages, which do not pose serious problems of identification. Phlomis $\times$ margaritae has shown a perfect pattern of additivity in isozyme variability between its putative parental taxa.

In the Iberian Peninsula the genus Phlomis is represented by four species (Mateu, 1986): P. herba-venti L. and $P$. purpurea L. with pink flowers, and $P$. crinita Cav. and $P$. lychnitis L. with yellow flowers. Despite this apparent simplicity, taxonomy of the two yellow-flowered taxa has been a matter of controversy since the early $20^{\text {th }}$ century apparently due to hybridization and introgression (e.g., Pau, 1918; Mateu, 1986; Rivas-Martínez $\&$ al., 1991). Phlomis lychnitis is distributed across the Iberian Peninsula and southern France (Bòlos \& Vigo, $1995)$ and hybridizes with $P$. crinita wherever their distribution ranges overlap in southern and eastern Spain (Andalusia and Levante, respectively). Both species are chamaephytes, being part of the Mediterranean vegetation in disturbed rocky soils. Phlomis crinita comprises two different subspecies following an eco-morpho-geographical pattern of variation (Albaladejo \& al., 2004). Phlomis crinita subsp. malacitana is restricted to mountains above $1000 \mathrm{~m}$ in Andalusia and frequently forms highly morphologically variable hybrid swarms with $P$. lychnitis. On the other hand, P. crinita subsp. crinita grows in Levante, in much drier habitats usually below $800 \mathrm{~m}$, where hybridization with $P$. lychnitis seems to be less important based on the observation that mixed populations consist of parental phenotypes with just a few intermediate individuals. All Iberian taxa are diploid $(2 n$ $=20$ ), and a higher frequency of meiotic irregularities (i.e., univalents and multivalents, chromatinic bridges, chromosome clumping and polysporads) have been found in mixed populations in Andalusia as compared to those in Levante. These results have been interpreted as the outcomes of a higher frequency of hybridization and introgression in Andalusia as compared to Levante (Aparicio \& Albaladejo, 2003).

The present study examines patterns of variation in nrDNA and cpDNA in the yellow-flowered Iberian endemic species in an effort to determine if effects caused by hybridization and introgression can be discriminated from those by lineage sorting resulting from recent diversification. In particular, we aimed at distinguishing reticulation and divergence processes in Iberian Phlomis by: (1) examining additive polymorphisms in ITS sequences and reconstructing phylogenies for these regions; (2) reconstructing maternal plastid phylogenies using non-coding regions; and (3) comparing nuclear and plastid lineages.

\section{MATERIALS AND METHODS}

Plant material. - The sampling was designed to cover the whole distribution range of the three taxa involved in the study, encompassing eight accessions from four localities of $P$. crinita subsp. crinita (Levante), 14 accessions from seven populations of $P$. crinita subsp. malacitana (Andalusia), and 23 accessions from 14 populations of $P$. lychnitis across Spain. We included two other taxa: three accessions from $P$. crinita subsp. mauritanica from three different locations in northern Africa and one accession of $P$. purpurea, which was used as outgroup (Appendix).

DNA isolation, PCR and sequencing. - Total DNA was isolated from silica-gel-dried leaves and occasionally from herbarium specimens using the DNeasy 96 Plant kit (Qiagen, Valencia, California, U.S.A.) according to manufacturer's protocols.

Polymerase chain reactions (PCR) were performed in $25 \mu \mathrm{l}$ reaction volume with $0.5 \mu \mathrm{l}(10 \mu \mathrm{M})$ of each primer using PuRe TaqTM Ready-To-GoTM PCR beads (Amersham Biosciences) and run in a GeneAmp PCR system 9700 (PE Biosystems, Foster City, California, U.S.A.) or a Mastercycler ${ }^{\circledR}$ PCR (Eppendorf AG, Hamburg). Double-strand amplification of the ITS region (ITS1+5.8s+ITS2) was performed with P1A and P4 primers (Fuertes Aguilar \& al., 1999b). The PCR profile for the amplification of the ITS region comprised an initial step of $94^{\circ} \mathrm{C}(5 \mathrm{~min}), 38$ cycles with $94^{\circ} \mathrm{C}(30 \mathrm{~s})$, $52^{\circ} \mathrm{C}(30 \mathrm{~s})$, and $72^{\circ} \mathrm{C}(60 \mathrm{~s})$ and a final extension step of $72^{\circ} \mathrm{C}$ (10 min). For a successful amplification of the ITS region, a $2.5 \mu \mathrm{l}$ volume of DMSO $(10 \% \mathrm{v} / \mathrm{v})$ was added.

Amplifications of the plastid regions were performed with primers trn-H and psb-A for the trnH-psbA intergenic spacer (Hamilton, 1999), trn- $a$ and $t r n-b$ for the trnT-trnL intergenic spacer (Taberlet \& al., 1991), and S1494R and RBCL1 for the atpB gene plus the atpB$r b c L$ intergenic spacer (Hoot \& al., 1995). PCR amplification profiles for plastid regions started with an initial step of $94^{\circ} \mathrm{C}$ for 5 min followed by 35 cycles with $94^{\circ} \mathrm{C}$ $(45 \mathrm{~s}), 53^{\circ} \mathrm{C}(60 \mathrm{~s}), 72^{\circ} \mathrm{C}(30 \mathrm{~s})$, and a final extension step of $72^{\circ} \mathrm{C}(7 \mathrm{~min})$ for the trnH-psbA intergenic spacer; 36 cycles with $94^{\circ} \mathrm{C}(30 \mathrm{~s}), 50^{\circ} \mathrm{C}(30 \mathrm{~s}), 72^{\circ} \mathrm{C}(60 \mathrm{~s})$, and a final step of $72^{\circ} \mathrm{C}(7 \mathrm{~min})$ for the trnT-trnL intergenic spacer; and, 37 cycles with $94^{\circ} \mathrm{C}(60 \mathrm{~s}), 56^{\circ} \mathrm{C}(60 \mathrm{~s}), 72^{\circ} \mathrm{C}$ 
(3 min), with a final step of $72^{\circ} \mathrm{C}(7 \mathrm{~min})$ for $a t p B-r b c L$.

Amplified PCR products were checked in $1.5 \%$ agarose gel electrophoresis in TAE (Tris-Acetate-EDTA) buffer, stained with ethidium bromide, and purified using the PCR Clean-Up kit (MoBio Laboratories, Solana Beach, California, U.S.A.) according to the manufacturer's protocols. Sequencing reactions were performed on both strands with the same primers as in amplifications using fluorescently labelled dideoxynucleotide terminators with the ABI Big-Dye Terminator kit (Applied Biosystems, Foster City, California, U.S.A.). Products were then separated on a ABI 3700 DNA sequencer at the Servicio de Secuenciación from CIB, CSIC, Madrid. Due to the length of the $a t p B-r b c L$ region, two specific internal primers were designed for complete sequencing. New reverse (5'-TGGATTCGATTGGATGTCA-3') and forward (5'-CTCGGAAATATTCCGCCATC-3') primers were used coupled with S1494R and RBCL1, respectively. Primers were developed with the help of the Primer3 program (Rozen \& Skaletsky, 2000).

Forward and reverse sequences for all regions were completely overlapped to create a consensus sequence. Sequences were manually aligned with BioEdit Sequence Alignment Editor (Hall, 1999). Polymorphic sites (PS) in the ITS sequences were assigned following criteria in Fuertes Aguilar \& al. (1999a, b) using the IUPAC ambiguity symbols. PS were considered additive (APS) (Fuertes Aguilar \& Nieto Feliner, 2003) when the two bases involved in the polymorphism were also found independently in other accessions. To confirm the expected additivity patterns in a recent $\left(\mathrm{F}_{1}\right)$ interspecific hybrid, we examined the ITS sequences of the known hybrid taxon $P$. xmargaritae (accessions 50 and 51) (Appendix). Identification of co-occurring ITS repeat copies (ribotypes) was inferred by subtraction (Clark, 1990), using the only two detected sequences that lacked polymorphisms as reference: ribotype 3 (R3) for P. crinita subsp. malacitana and R13 for $P$. lychnitis (see Results). Alignment of the sequences from the three different chloroplast regions was straightforward due to the low variability. All sequences have been submitted to GenBank (Appendix).

Data analysis. - ITS and chloroplast sequences were analysed using both maximum and statistical parsimony. For maximum parsimony analyses, the following strategy was followed. Characters were treated as unordered and gaps, as well as non-additive polymorphic sites, as missing data. The search for the most parsimonious trees was performed with PAUP* $4.0 \mathrm{~b} 10$ (Swofford, 2001) using heuristic searches with 100 random taxon addition, TBR and ACCTRAN options in branch swapping and character optimisation respectively, and no max trees limit. Bootstrap analyses (100000 replicates) were performed with the "fast" stepwise-addi- tion (see Mort \& al., 2000 for a discussion about the fast bootstrapping procedure) as implemented in PAUP* to assess the relative support of the clades. For ITS, a first phylogenetic analysis including all the sequences was unable to complete the search for all possible parsimonious trees (results not shown). Detailed examination of sequences allowed the identification of two individuals as the source of conflict and multiplication of most parsimonious topologies (accessions 38 and 39, see Discussion). Once those four sequences ( 2 per sample) were removed, a new search was performed. For plastid sequences, each region was first analyzed independently. Due to the high consistency of results found in the three plastid regions, sequences were combined to create a single data matrix.

In addition, statistical parsimony analysis of ribotypes and haplotypes was conducted using the algorithm described in Templeton \& al. (1992). This method reconstructs relationships among haplotypes as networks, which allow loops and polytomies, and is thus particularly appropriate for intraspecific datasets. Networks were constructed using TCS 1.13 (Clement \& al., 2000), with gaps coded as missing data.

\section{RESULTS}

ITS sequences. - In Phlomis, the ITS (ITS1+5.8s+ITS2) region ranged between 672 and 676 bp ( $P$. crinita subsp. mauritanica and $P$. purpurea, respectively). The sequences were $674 \mathrm{bp}$ long in $P$. lychnitis, $P$. crinita subsp. crinita and $P$. crinita subsp. malacitana. Thirty-one variable sites were detected $(4.6 \%)$ and 17 of them $(2.5 \%)$ were parsimony-informative. When the sequence from the outgroup was excluded only seven sites remained variable $(1.0 \%)$, of which six were parsimony-informative. The whole dataset excluding $P$. $\times$ margaritae contained $12 \mathrm{PS}$, all of them in P. lychnitis, $P$. crinita subsp. crinita and $P$. crinita subsp. malacitana sequences (Table 1). Six of those 12 PS were additive.

Twelve of the 23 sequences from $P$. lychnitis were identical and did not contain intraindividual polymorphisms, and consequently were considered the "pure" species sequence, whereas the remaining 11 showed 1-3 PS. Polymorphisms in $P$. crinita subsp. malacitana sequences ranged from zero (accession 24, hereby considered the "pure" subspecies sequence) to four (accession 34). Differences between the $P$. lychnitis and $P$. crinita subsp. malacitana "pure" sequences involved only five nucleotide sites (positions 95, 100, 132, 587 and 609; Table 1). All the eight ITS sequences from $P$. crinita subsp. crinita have PS. Accessions 38 and 39 showed the same bases as the $P$. lychnitis species sequence at positions 95,100 and 587, a single exclusive 
point mutation (position 204) and one APS (position 132) combining the nucleotides from $P$. lychnitis and $P$. crinita subsp. malacitana. Accessions $40-45$ did not show any exclusive mutation and were characterized by the presence of two APS (position 95 and 100) combining the nucleotides from $P$. lychnitis and $P$. crinita subsp. malacitana. Positions 132 and 609 in these sequences displayed $P$. crinita subsp. malacitana nucleotides whereas position 587 showed the $P$. lychnitis nucleotide.

The ITS sequences for $P$. purpurea and $P$. crinita subsp. malacitana differed at 22 nucleotide sites including two indels. The two ITS sequences from their putative hybrid $P$. Xmargaritae showed the expected nucleotide additive polymorphisms for 21 of those sites, the only exception being site 172 which may be due to ITS polymorphisms within $P$. purpurea (Table 1).

Maximum parsimony analysis of inferred ribotypes (excluding $P$. crinita subsp. crinita accessions 38 and 39) yielded 42 equally most parsimonious trees $(\mathrm{L}=42$; C.I. $=0.83$, excluding uninformative characters; R.I. $=0.97$ ).

The strict consensus tree (Fig. 1) shows two main sister clades: one with all the three samples of $P$. crinita subsp. mauritanica, displaying ribotype 4 (R4) (100\% bootstrap support), and a large clade including all $P$. crinitallychnitis samples ( $76 \%$ bootstrap support). The latter was composed of two largely unresolved clades that include accessions of $P$. crinita and P. lychnitis, respectively. The Iberian $P$. crinita clade includes all $P$. crinita subsp. crinita and $P$. crinita subsp. malacitana accessions harbouring ribotypes $\mathrm{R} 3$ and $\mathrm{R} 5-10$. The $P$. lychnitis clade comprises all the $P$. lychnitis accessions, presenting ribotypes R13-21.

The statistical parsimony analysis of the inferred ITS ribotypes yielded a network containing all the eighteen ribotypes found in P. lychnitis and in both Iberian subspecies of $P$. crinita, while those found in $P$. crinita subsp. mauritanica and $P$. purpurea appeared unconnected (Fig. 2). The network showed two main groups of ribotypes, with those from $P$. lychnitis connected to those from $P$. crinita through R15. No ribotypes were shared by $P$. lychnitis and P. crinita (both subspecies), while subspecies crinita and malacitana shared two ribotypes (R5 and R10).

Plastid DNA sequences. - In contrast to the ITS region, the distribution pattern of the plastid DNA markers was geographic rather than taxonomic. The trnH-psbA intergenic spacer ranged from 287-288 bp due to the existence of a $1 \mathrm{bp}$ indel. This region was characterized by the presence of a $26 \mathrm{bp}$ inversion. In order to avoid overestimating rates of sequence divergence in phylogenetic reconstruction, this inversion was eliminated from the analysis and coded as a single point mutation (e.g., Sang \& al., 1997). Six variable positions were found $(2.1 \%)$, three of them were parsimony-informative

Table 1. Nucleotide site variation in the ITS region of the studied Phlomis taxa from the western Mediterranean area. Ribotypes were identified by subtraction from sequences with polymorphic sites, using those with no polymorphisms as reference (see text for details). Polymorphic sites denoted using IUPAC ambiguity symbols $(K=G+T ; M=A+C ; R$ $=A+G ; S=C+G ; Y=C+T)$.

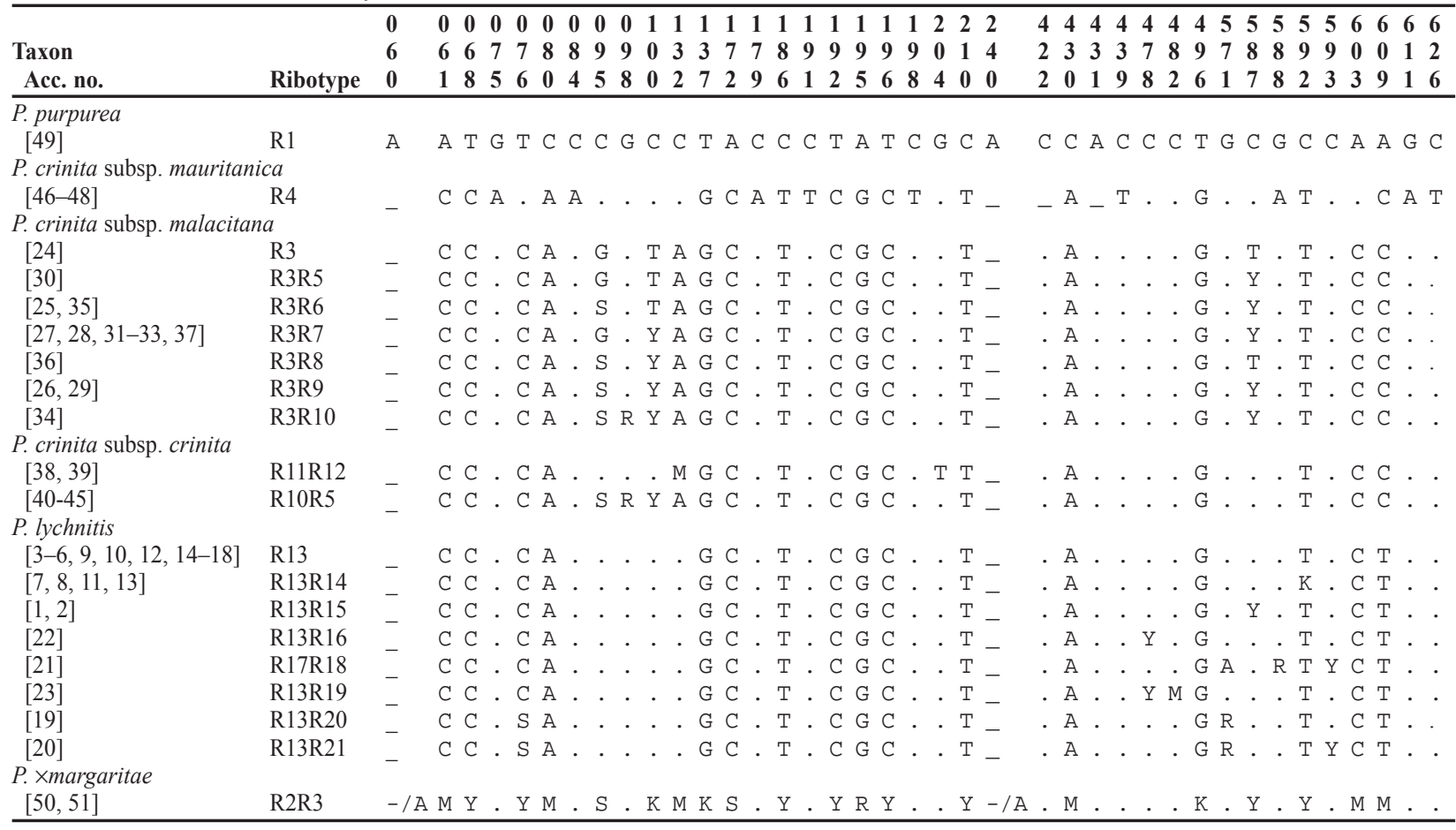




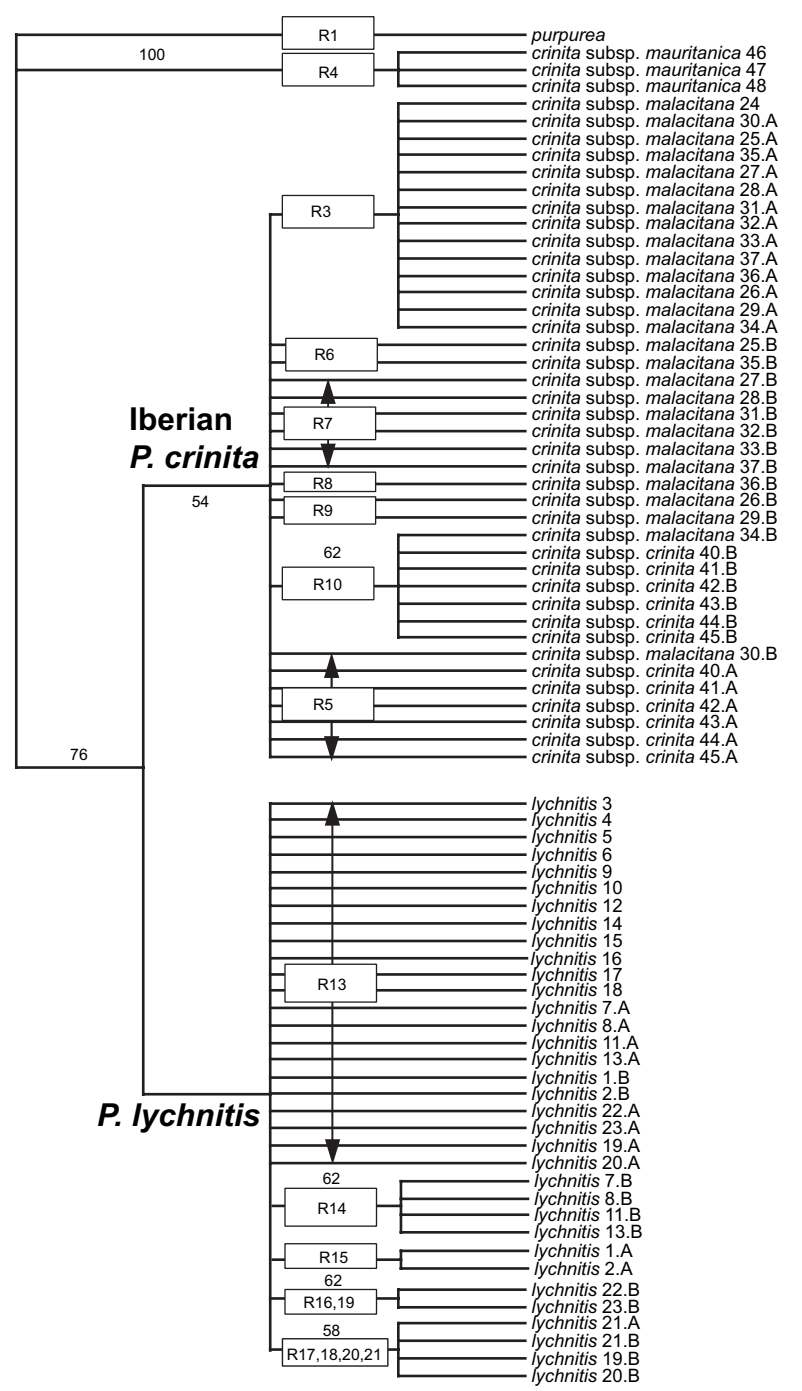

Fig. 1. Strict consensus tree of 42 most parsimonious trees obtained from the analysis of the inferred ribotypes from ITS sequences of Phlomis. $L=42$ steps, C.I. $=0.83$, excluding uninformative characters and R.I. $=0.97$. Bootstrap values above $\mathbf{5 0 \%}$ are shown along the branches. R1 - R21 identify different ribotypes based on ITS sequences. Two ribotypes inferred from one single sample are indicated by an accession number followed by ' $A$ ' or 'B'.

$(1.0 \%)$ and three were autapomorphic, which allowed recognizing seven haplotypes across the dataset (outgroup included, Table 2). Maximum parsimony analysis of haplotypes resulted in a single most parsimonious tree containing no homoplasy $(\mathrm{L}=6$; C.I. $=1.00$, excluding uninformative characters; R.I. $=1.00)$.

The 49 aligned sequences of the trnT-trnL intergenic spacer were $689 \mathrm{bp}$ long. No indels were detected, nine characters were variable (1.3\%), and six of them were found to be parsimony-informative $(0.9 \%)$. These variable sites produced six different haplotypes, two of them exclusive to $P$. purpurea and $P$. crinita subsp. mauritani- $c a$, respectively. Along with the trnH-psbA region, the other four trnT-trnL haplotypes followed a geographical distribution pattern. Maximum parsimony reconstruction of haplotypes yielded a single most parsimonious tree containing no homoplasy $(\mathrm{L}=9$; C.I. $=1.00$, excluding uninformative characters; R.I. $=1.00)$.

The aligned matrix of the $a t p B-r b c L$ region was 2240 bp long. Despite being the largest plastid marker sequenced, it displayed the lowest level of variability. Two indels were detected and only 12 sites were found to be variable $(0.5 \%)$, of which seven were parsimonyinformative $(0.3 \%)$. Five haplotypes were identified, two of them restricted to P. purpurea and P. crinita subsp. mauritanica, so that only three were found in accessions of $P$. lychnitis, $P$. crinita subsp. malacitana and $P$. crinita subsp. crinita (Table 2). When the aligned data matrix was subjected to maximum parsimony analysis, a single most parsimonious tree containing no homoplasy was recovered $(\mathrm{L}=12 ;$ C.I. $=1.00$, excluding uninformative characters; R.I. $=1.00)$.

The aligned matrix of the combined sequences from the three chloroplast markers was $3217 \mathrm{bp}$ long. Maximum parsimony analysis of the 49 sequences produced 23 most-parsimonious trees of 29 steps with a consistency index (C.I.) of 0.889 , excluding uninformative characters, and a retention index (R.I.) of 0.919. The strict consensus tree (Fig. 3) shows three main clades, supported by high bootstrap values, which collapse in a basal trichotomy. A taxon-specific clade, supported by five synapomorphies, includes the three accessions of $P$. crinita subsp. mauritanica (99\% bootstrap). The other two large clades, here termed Andalusian clade (95\% bootstrap) and Levante clade (87\% bootstrap), respectively, show very low within-clade resolution. The Andalusian clade is supported by three synapomorphies and consists of a completely unresolved polytomy (due to the fact that most sequences are identical and to the lack of withinclade synapomorphies). This clade includes all $P$. crinita subsp. malacitana and $P$. lychnitis accessions from southern Spain plus the two P. lychnitis accessions (20 and 21) sampled from western Spain. The Levante clade is supported by two synapomorphic character changes and comprises all $P$. crinita subsp. crinita and $P$. lychnitis accessions from eastern Spain plus the remaining $P$. lychnitis accessions sampled from other areas of the complex (central and northeastern Spain). In addition, this clade also includes two $P$. lychnitis and two $P$. crinita subsp. malacitana accessions (numbers 7, 8 and 30, 31, respectively) from southern Spain. Although some internal resolution could be detected within this Levante clade, bootstrap support values were low $(<70 \%)$.

The statistical parsimony analysis of the combined chloroplast sequences yielded one single network containing all the haplotypes found in the sampled taxa 


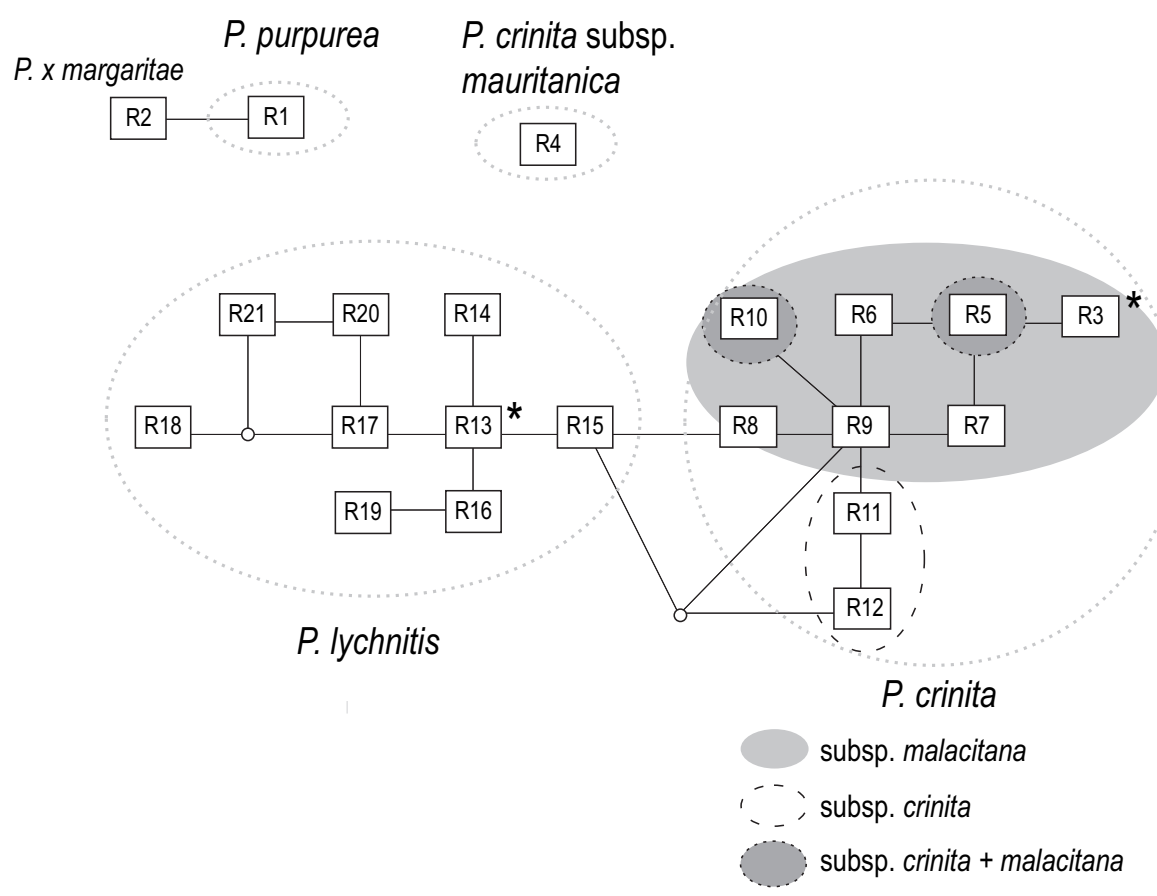

Fig. 2. Statistical parsimony network of inferred ribotypes from direct ITS sequences of Phlomis. Lines represent single mutational steps and circles represent missing ribotypes in the sampling. Asterisks indicate the 'pure' sequences in $P$. lychnitis and $P$. crinita subsp. malacitana (see text).

(Fig. 4). Across the network, four main groups of haplotypes can be distinguished, separated by several mutational steps that correspond to unsampled or non-existing haplotypes. Two of these groups include the 10 haplotypes found in the Iberian samples of the $P$. crinitallychnitis complex (A-J). Both groups, separated by five mutational steps, match the Andalusian and Levante clades recognized in the maximum parsimony analysis. Haplotypes found in P. crinita subsp. mauritanica and $P$. purpurea fall in the tip of two branches separated from the nearest haplotype $\mathrm{G}$ found in P. crinita subsp. crinita by 6 and 11 mutational steps, respectively (Fig. 4).

Haplotypes A to F were found in southern and western Spain whereas haplotypes G to I were found in eastern, central and northeastern Spain (Fig. 4). Haplotype J was the only one found in both southern and eastern Spain. Six haplotypes were detected in Phlomis lychnitis, two were unique $(\mathrm{C}, \mathrm{F})$, two were shared with $P$. crinita subsp. malacitana (A, J), and two were shared with $P$. crinita subsp. crinita $(\mathrm{H}, \mathrm{I})$. It is noteworthy that none of the haplotypes detected were shared by the two subspecies crinita and malacitana.

\section{DISCUSSION}

ITS evidence. - One significant feature of ITS sequences in the studied Iberian Phlomis is that most of them present PS: P. lychnitis ( $48 \%$ of the sequences), $P$. crinita subsp. malacitana (93\%), and P. crinita subsp. crinita $(100 \%)$. The existence of such PS reflects intragenomic co-occurrence of different ITS copies in the same genome despite the supposedly rapid homogenization that takes place in this tandemly-repeated region by means of concerted evolution (Zimmer \& al., 1980). Only individuals from $P$. lychnitis and $P$. crinita subsp. malacitana show sequences where, apparently, one single ITS copy (ribotype), R3 and R13, respectively, is detected. When PS occur, it is crucial to identify the underlying ribotypes causing the polymorphism in order to extract historical information. A clear observation can be drawn from the ribotypes' spectrum (Table 1); while there are no ribotypes shared between P. lychnitis and either subspecies of $P$. crinita, ribotypes 5 and 10 are present in $P$. crinita subsp. crinita and $P$. crinita subsp. malacitana, which is congruent with the integrity of $P$. crinita and P. lychnitis as two separate lineages. This conclusion is consistent with parsimony analysis (Fig. 1) where ribotypes detected in $P$. crinita subsp. crinita and P. crinita subsp. malacitana fall, albeit with low bootstrap value, into the same clade. Thus, molecular data support the morphological evidence and the taxonomic criterion that consider $P$. crinita and $P$. lychnitis as separate species. Statistical parsimony analysis (Fig. 2) agrees with it in that ribotypes from $P$. lychnitis and $P$. crinita belong to different lineages. The network shows 
Table 2. List of haplotypes in the studied diploid Phlomis taxa, with indication of nucleotide site variation within three chloroplast regions.

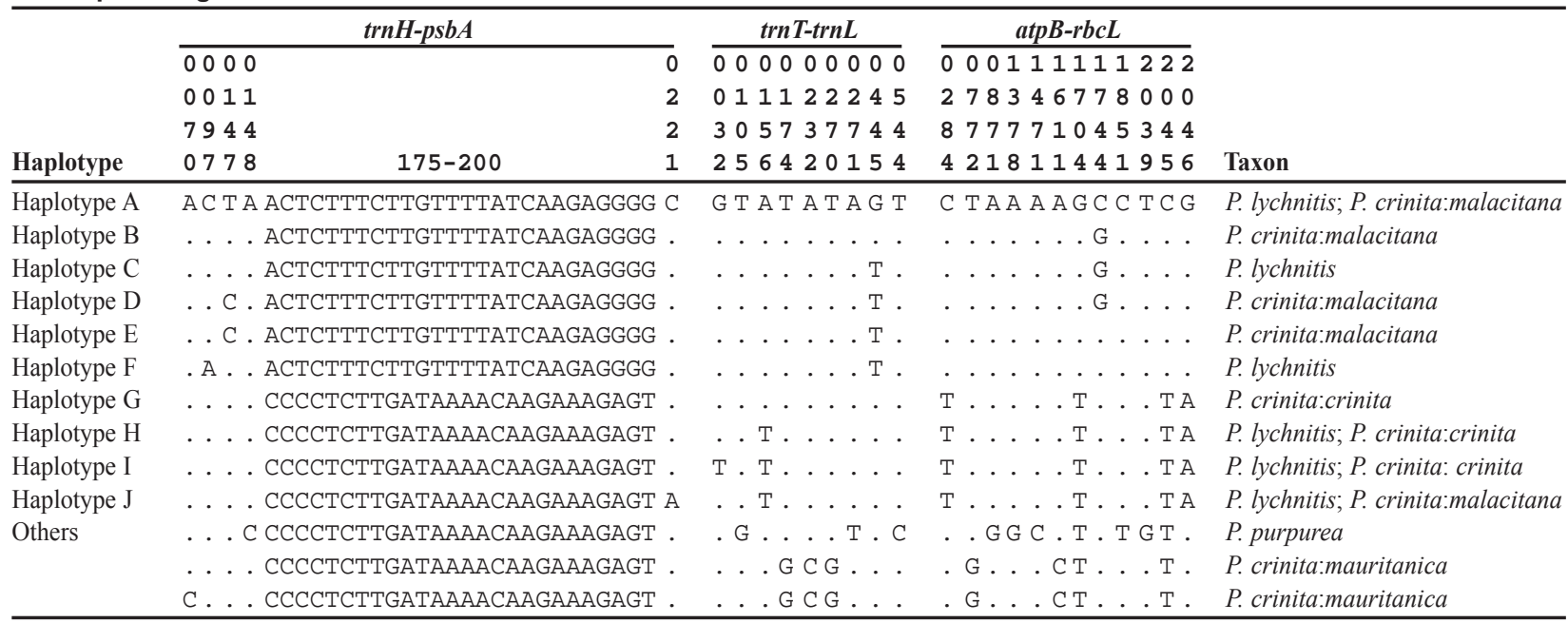

that $P$. lychnitis is linked to $P$. crinita by two branches, both of them through R15, separated by one and two mutational steps. The fact that $P$. crinita subsp. mauritanica appears unconnected to the other two subspecies (i.e., separated by more than 11 mutational steps) strengthens the closeness of $P$. crinita and $P$. lychnitis, which may be sister taxa. A systematic revision of $P$. crinita is therefore advisable.

The presence of different ribotypes in the same genome has been frequently interpreted as an outcome of past reticulation events between divergent lineages either at the polyploid (Campbell \& al., 1997; Vargas \& al., 1999; Hodkinson \& al., 2002; Yonemori \& al., 2002) or diploid level (Wichman \& al., 2002; Fuertes Aguilar \& Nieto Feliner, 2003; Marhold \& al., 2004). There is evidence suggesting that polymorphisms in Phlomis might be acquired by hybridization in our study. First, intraindividual heterogeneity occurred in a genetically confirmed hybrid taxon (P. ×margaritae), and such heterogeneity matched the additive combination of ITS sequences from the two putative parental taxa (P. purpurea and $P$. crinita subsp. malacitana). Second, extensive hybridization and introgression between $P$. crinita subsp. malacitana and $P$. lychnitis seems to occur based on the patterns of meiotic abnormalities (Aparicio \& Albaladejo, 2003) and morphological variability in Andalusian populations where both taxa are sympatric (Albaladejo \& al., 2004). In fact, the absence of nonpolymorphic ITS sequences in the eight studied samples of $P$. crinita subsp. crinita, might suggest a hybrid origin for this taxon.

However, assuming R3 and R13 as the "pure" $P$. crinita subsp. malacitana and $P$. lychnitis ribotypes, respectively, based on the frequency of appearance in the former taxon and on the lack of APS in the latter taxon, the APS pattern observed in $P$. crinita subsp. crinita is only partially congruent with a sum of both ribotypes. If we subtract ribotype R3 from $P$. crinita subsp. crinita sequences, we do not obtain an R13 ribotype, in particular for position 609, which is diagnostic for each species. Recent hybridization events are not satisfactory explanations for the origin of the two detected APS in P. crinita subsp. crinita because the number of differing positions

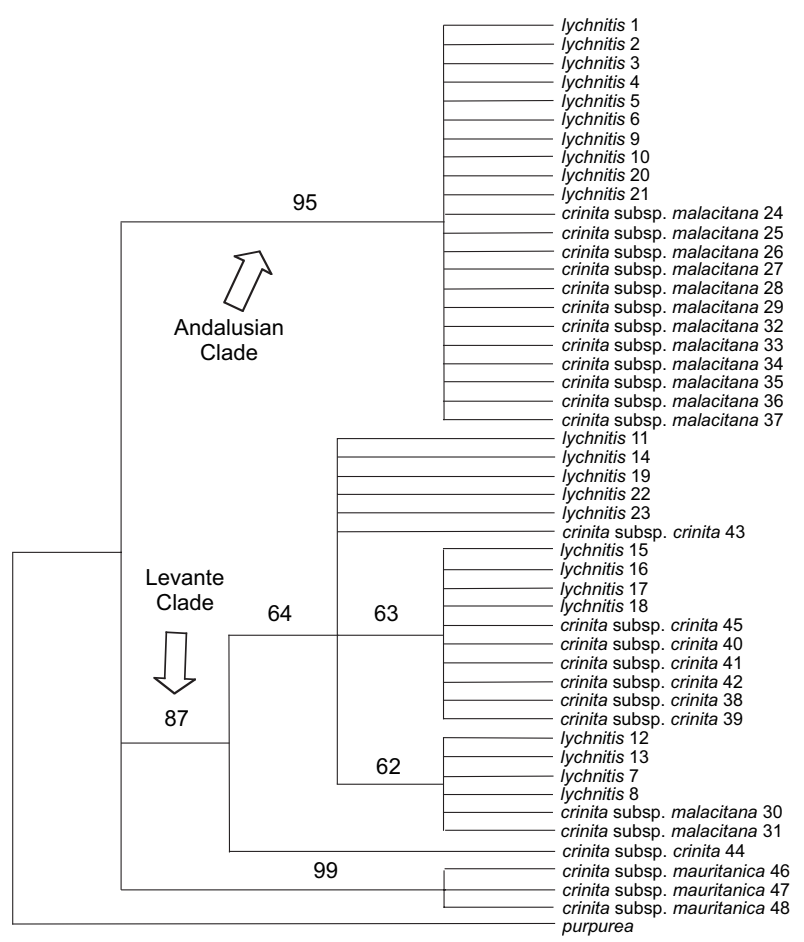

Fig. 3. Strict consensus tree of 23 most parsimonious trees obtained from the analysis of the combined data matrix of the trnH-psbA, trnT-trnL and atpB-rbcL chloroplast sequences. $L=29$ steps, C.I. $=0.889$, excluding uninformative characters and R.I. $=0.919$. Bootstrap values are shown above the branches. 

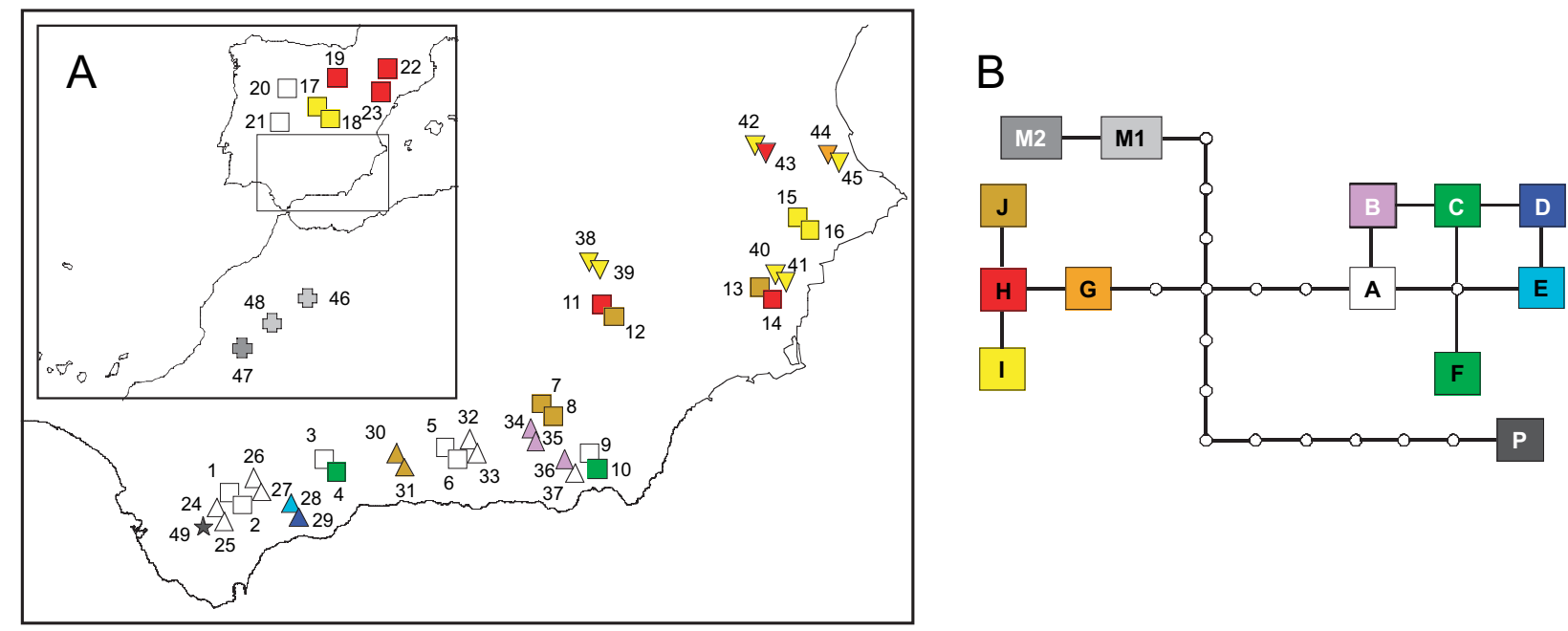

Fig. 4. A, Geographical distribution of 10 plastid haplotypes (A-J) in Phlomis crinita subsp. crinita (inverted triangles), $P$. crinita subsp. malacitana (triangles), and $P$. lychnitis (squares) samples based on combined sequences from three non-coding chloroplast regions (trnH-psbA, trnT-trnL and atpB-rbcL). Phlomis crinita subsp. mauritanica (crosses) and $P$. purpurea (star) haplotypes are also shown; B, statistical parsimony haplotype network based on the same combined sequences. Lines represent single mutational steps, and circles represent missing haplotypes.

between $P$. lychnitis and $P$. crinita subsp. malacitana species sequences is five whereas the number of additive sites in the $P$. crinita subsp. crinita sequences is one and two, respectively (Table 1). Further, even though hybridization seems to occur frequently in Phlomis and all samples of $P$. crinita subsp. crinita and most of $P$. crinita subsp. malacitana contain APS, those APS might also reflect ancestral polymorphisms within the $P$. crini$t a$ lineage or intergradation between partially differentiated populations or subspecies of the same lineage.

Unlike most ITS sequences containing APS, which we cannot readily attribute to hybridization, those from Elche de la Sierra (accessions 38 and 39) may well be the result of rare hybridization between $P$. lychnitis and $P$. crinita subsp. malacitana. Of five diagnostic positions, both individuals bear three positions with the $P$. lychnitis nucleotide (Table 1). For the fourth position (132) the two samples present an APS, while the fifth displays the P. crinita base (C in position 609). This chimerical ribotype might be the result of a recombination between R3 and $\mathrm{R} 13$ ribotypes, an outcome that has been reported to result from past hybridization events in other plants (Roelofs \& al., 1997; Wendel \& al., 1995; Nieto Feliner $\&$ al., 2004). Three independent additional sources of evidence support this explanation. (1) P. lychnitis does not currently occur with that population of $P$. crinita subsp. crinita, which rejects a recent introgression event. (2) A genetic distance tree based on isozymes places the Elche de la Sierra population much closer to P. lychnitis than to both subspecies of $P$. crinita despite morphological coherence with the latter (Albaladejo \& Aparicio, unpubl.). (3) While in the ribotype network (Fig. 2) ribo- types detected in $P$. crinita connect directly to R15 of $P$. lychnitis, suggesting a gradual evolution and therefore a sister relationship, ribotypes $\mathrm{R} 11$ and $\mathrm{R} 12$ are linked to R15 through a missing ribotype, which is more consistent with a recombination event (Chiang \& al., 2001). The possibility that these sequences resulted from recombination would explain the conflicts caused in the maximum parsimony analysis and thus would justify removing them from the analysis (Fuertes Aguilar \& Nieto Feliner, 2003).

Plastid evidence. - A significant conclusion of this study is the contrasting patterns observed between plastid and nuclear markers, revealing that both types of markers convey different historical information. Low mutation rate in chloroplast DNA combined with frequent instances of hybridization in Phlomis, may have generated the current haplotype distribution, which could be the result of a sorting of ancient variation in space and through time (Hewitt, 2000). To integrate the apparently discordant plastid and nuclear evidence, we suggest that both lineage sorting and horizontal transfer have been involved.

Non-coding plastid regions sequenced in this study span a considerable stretch of the chloroplast genome (3217 bp), suggesting that there are good chances to recover phylogenetic signal from the maternal lineage of this group of related species. Variability is limited, resulting in 13 haplotypes across the studied taxa, but the three regions sampled are largely congruent, as demonstrated by the fact that homoplasy is very low in the combined chloroplast dataset (C.I. $=0.889$; R.I. $=0.919)$. Low variability can be indicative of a recent divergence time for 
the accumulation of novel mutations (McKinnon \& al., 1999), despite morphological differentiation among taxa (Albaladejo \& al., 2004).

The pattern of variation of haplotypes is to a large extent geographic. There are two groups of haplotypes, separated by four "empty" mutational steps, which correspond to two different areas: southern and western Spain on one hand and eastern Spain on the other. The only exception is haplotype J, which occurs in both areas (Fig. 4). The pattern of variation of plastid sequence data is also species-independent based on the fact that $P$. crinita subsp. malacitana and $P$. crinita subsp. crinita did not share any haplotype and that $P$. lychnitis shared haplotypes with both subspecies, depending on the area. This pattern of chloroplast DNA haplotype variation is incongruent with that found in nuclear ITS sequences, which matched to some extent morphology, taxonomy, and isozyme data (Albaladejo \& al., 2004; Albaladejo \& Aparicio, unpubl.). In plants, cases of haplotype variability showing better fit with geographical distribution than with taxonomic boundaries have been reported in Eucalyptus (Jackson \& al., 1999; McKinnon \& al., 1999), Helianthus (Rieseberg, 1991), Penstemon (Wolfe \& Elisens, 1995) and Quercus (Ferris \& al., 1993; Whittemore \& Schaal, 1991). Most cases have been interpreted in terms of hybridization and introgression. However, unlike other systems (Nieto Feliner \& al., 2004), in Phlomis the geographical pattern does not seem to occur at a fine scale in the form of haplotype sharing by different taxa within the same location.

The fact that $P$. crinita subsp. crinita lacks exclusive haplotypes, except for the singleton $\mathrm{G}$, together with its geographical pattern of variation, could suggest that this taxon has arisen from hybridization between $P$. crinita subsp. malacitana and $P$. lychnitis. One such process would be facilitated by the frequency of hybridization detected among the Iberian Phlomis (Aparicio \& Albaladejo, 2003; Albaladejo \& al., 2004) and would also be compatible with the experimental evidence that crosses of those two taxa with $P$. lychnitis as maternal parent are more viable than the reciprocal (Albaladejo \& Aparicio, unpubl.). Taking this evidence into account, it would be conceivable that haplotypes shared by P. crinita subsp. crinita and P. lychnitis come from the P. lychnitis lineage.

However, as discussed above, we fail to find traces in nuclear markers of a single hybridization event that gave rise to $P$. crinita subsp. crinita. There are traces of hybridization in ITS sequences in the form of APS but they do not affect all the samples of $P$. crinita subsp. crinita so as to suggest that a single hybridization event might have generated the taxon.

Lineage sorting may have been responsible for the sharing of ancestral haplotype A by $P$. lychnitis and $P$. crinita subsp. malacitana, since it is the most frequent in both taxa and has an interior position in the haplotype network. Besides, if we compare the distribution of haplotypes and ITS ribotypes, haplotype A is also the most frequent in those samples of $P$. lychnitis displaying R13 (the "pure" sequences for this species) and the one present in the only sample of $P$. crinita subsp. malacitana bearing R3 (the "pure" sequence for this species). Haplotypes $\mathrm{H}$ (one sample in $P$. crinita subsp. crinita, five in P. lychnitis) and $\mathrm{J}$ (two samples in P. crinita subsp. malacitana, four in P. lychnitis) may belong to the $P$. lychnitis lineage and have been transferred horizontally to subspecies crinita and malacitana, respectively (Fig. 4). In the case of $\mathrm{H}$, not only are the different frequencies in both taxa compatible with this hypothesis (although based on a limited sampling) but also the geographic distribution of the haplotype outside the areas of sympatry. In the case of $\mathrm{J}$, the distance across the parsimony network (seven mutational steps apart) with respect to the other haplotypes found in P. crinita subsp. malacitana reduces the possibility of lineage sorting. Haplotype I has been found in six samples of $P$. crinita subsp. crinita and four of $P$. lychnitis. It occurs mainly in the two taxa in the eastern Spanish sympatric area but also in two inland samples of $P$. lychnitis. It cannot be determined whether the sharing of this haplotype by both taxa is due to lineage sorting or to horizontal transfer.

Concluding remarks. - Distinguishing between hybridization and recent divergence is inherently complex (Allan \& al., 1997; Nieto Feliner \& al., 2002; Archibald \& al., 2004). This is particularly so in southern European refugia where both processes have subsequently occurred as a result of expansion and contraction cycles of distribution areas (Gutiérrez Larena \& al., 2002; Hewitt, 2004). Conclusively disentangling hybridization and recent divergence in the case study presented here is not possible. However, the available data suggest evidence of two sister lineages where cases of localized hybridization can be identified despite the frequent occurrence of retained ancestral polymorphisms.

\section{ACKNOWLEDGEMENTS}

This study was supported by the Spanish Ministry of Science and Technology (grant BOS2000-0450). The authors thank I. Álvarez, S. Cozzolino and an anonymous reviewer for helpful comments, Andrea Costa for technical support, and the authorities of the Andalusian Natural Parks for their permission to sample materials. 


\section{LITERATURE CITED}

Albaladejo, R. G., Aparicio, A. \& Silvestre, S. 2004. Variation patterns in the Phlomis composita (Lamiaceae) hybrid complex in the Iberian Peninsula. Bot. J. Linn. Soc. 145: 97-108.

Allan, G. J., Clark, C. \& Rieseberg L. H. 1997. Distribution of parental DNA markers in Encelia virginensis (Asteraceae: Heliantheae), a diploid species of putative hybrid origin. Pl. Syst. Evol. 205: 205-221.

Álvarez, I. \& Wendel, J. F. 2003. Ribosomal ITS sequences and plant phylogenetic inference. Molec. Phylogen. Evol. 29: 417-434.

Aparicio, A. \& Albaladejo, R. G. 2003. Microsporogenesis and meiotic abnormalities in the hybrid complex of Phlomis composita (Lamiaceae). Bot. J. Linn. Soc. 143: 79-85.

Aparicio, A., Albaladejo, R. G., Porras, M. \& Ceballos, G. 2000. Isozyme evidence for natural hybridization in Phlomis (Lamiaceae): hybrid origin of the rare P. margaritae. Ann. Bot. 85: 7-12.

Archibald, J. K., Wolfe, A. D. \& Johnson, S. D. 2004. Hybridization and gene flow between a day- and nightflowering species of Zaluzianskya (Scrophulariaceae s.s., tribe Manuleeae). Amer. J. Bot. 91: 1333-1344.

Azizian, D. \& Moore, D. M. 1982. Morphological and palynological studies in Phlomis L. and Eremostachys Bunge (Labiatae). Bot. J. Linn. Soc. 85: 249-281.

Baldwin, B. G., Sanderson, M. J., Porter, J. M., Wojciechowski, M. F., Campbell, C. S. \& Donoghue, M. J. 1995. The ITS region of nuclear ribosomal DNA: a valuable source of evidence on angiosperm phylogeny. Ann. Missouri Bot. Gard. 82: 247-277.

Bolòs, O. \& Vigo, J. 1995. Flora dels Països Catalans, vol. III. Editorial Barcino, Barcelona.

Campbell, C. S., Wojciechowski, M. F., Baldwin, B. G., Alice, L. A. \& Donoghue, M. J. 1997. Persistent nuclear ribosomal DNA sequence polymorphism in the Amelanchier agamic complex (Rosaceae). Molec. Biol. Evol. 14: 81-90.

Chiang, T. Y., Hong, K. H. \& Peng, C. I. 2001. Experimental hybridization reveals biased inheritance of the internal transcribed spacer of the nuclear ribosomal DNA in Begonia $\times$ taipeiensis. J. Pl. Res. 114: 343-351.

Clark, A. G. 1990. Inference of haplotypes from PCR-amplified samples of diploid populations. Molec. Biol. Evol. 7: 111-122.

Clement, M., Posada, D. \& Crandall, K. A. 2000. TCS: a computer program to estimate gene genealogies. Molec. Ecol. 9: 1657-1660.

Dadandi, M. Y. \& Duman, H. 2003. A new natural hybrid of Phlomis (Lamiaceae) from Turkey. Ann. Bot. Fenn. 40: 287-290.

Ferris, C., Oliver, R. P., Davy, A. J. \& Hewitt, G. M. 1993. Native oak chloroplasts reveal an ancient divide across Europe. Molec. Ecol. 2: 337-344.

Fuertes Aguilar, J. \& Nieto Feliner, G. 2003. Additive polymorphisms and reticulation in an ITS phylogeny of thrifts (Armeria, Plumbaginaceae). Molec. Phylogen. Evol. 28: 430-447.

Fuertes Aguilar, J., Roselló, J. A. \& Nieto Feliner, G. 1999a.
Nuclear ribosomal DNA (nrDNA) concerted evolution in natural and artificial hybrids of Armeria (Plumbaginaceae). Molec. Ecol. 8: 1341-1346.

Fuertes Aguilar, J., Roselló, J. A. \& Nieto Feliner, G. 1999b. Molecular evidence for the compilospecies model of reticulate evolution in Armeria (Plumbaginaceae). Syst. Biol. 48: 735-754.

Gutiérrez Larena, B., Fuertes Aguilar, J. \& Nieto Feliner, G. 2002. Glacial-induced altitudinal migrations in Armeria (Plumbaginaceae) inferred from patterns of chloroplast DNA haplotype sharing. Molec. Ecol. 11: 1965-1974.

Hall, T. A. 1999. BioEdit: a user-friendly biological sequence alignment editor and analysis program for Windows 95/98/NT. Nucl. Acids. Symp. Ser. 41: 95-98.

Hamilton, M. B. 1999. Four primers pairs for the amplification of chloroplast intergenic regions with intraspecific variation. Molec. Ecol. 8: 521-525.

Hampe, A., Arroyo, J., Jordano, P. \& Petit, R. J. 2004. Rangewide phylogeography of a bird-dispersed Eurasian shrub: contrasting Mediterranean and temperate glacial refugia. Molec. Ecol. 12: 3415-3426.

Hewitt, G. M. 2000. The genetic legacy of the ice ages. Nature 405: 907-913.

Hewitt, G. M. 2004. Genetic consequences of climatic oscillations in the Quaternary. Philos. T. Roy. Soc. B 359: 183-195.

Hodkinson, T. R., Chase, M. V., Takahashi, C., Leitch, I. J., Bennett, M. D. \& Renvoize, S. A. 2002. The use of DNA sequencing (ITS and trnL-F), AFLP, and fluorescent in situ hybridization to study allopolyploid Miscanthus (Poaceae). Amer. J. Bot. 89: 279-286.

Hoot, S. B., Culham, A. \& Crane, P. R. 1995. The utility of $a t p B$ gene sequences in resolving phylogenetic relationships: comparison with $r b c L$ and $18 \mathrm{~S}$ ribosomal DNA sequences in the Lardizabalaceae. Ann. Missouri Bot. Gard. 82: 194-207.

Huber-Morath, A. 1982. Phlomis. Pp. 102-126 in: Davis, P. H. (ed.), Flora of Turkey. Edinburgh Univ. Press, Edinburgh.

Jackson, H. D., Steane, D. A., Potts, B. M. \& Vaillancourt, R. E. 1999. Chloroplast DNA evidence for reticulate evolution in Eucalyptus (Myrtaceae). Molec. Ecol. 8: 739-751.

Marhold, K., Lihová, J., Perný, M. \& Bleeker, W. 2004. Comparative ITS and AFLP analysis of diploid Cardamine (Brassicaceae) taxa from closely related polyploid complexes. Ann. Bot. 93: 507-520.

Mateu, I. 1986. Revisión del género Phlomis L. (Labiatae) en la Península Ibérica e Islas Baleares. Acta Bot. Malacitana 11: 177-204.

McKinnon, G. E., Steane, D. A., Potts, B. M. \& Vaillancourt, R. E. 1999. Incongruence between chloroplast and species phylogenies in Eucalyptus subgenus Monocalyptus (Myrtaceae). Amer. J. Bot. 86: 1038-1046.

Mort, M. E., Soltis, P. S., Soltis, D. E. \& Mabry, M. L. 2000. Comparison of three methods for estimating internal support on phylogenetic trees. Syst. Biol. 49: 160-171.

Nieto Feliner, G., Fuertes Aguilar, J. \& Roselló, J. A. 2002. Reticulation or divergence: the origin of a rare serpentine endemic assessed with chloroplast, nuclear and RAPD markers. Pl. Syst. Evol. 231: 19-38.

Nieto Feliner, G., Gutiérrez Larena, B. \& Fuertes Aguilar, J. 2004. Fine-scale geographical structure, intra-individual 
polymorphism and recombination in nuclear ribosomal internal transcribed spacer in Armeria (Plumbaginaceae). Ann. Bot. 93: 189-200.

Pau, C. 1918. Una ligera visita botánica a Tous. Bull. Inst. Catalana Hist. Nat. 18: 158-161.

Rieseberg, L. H. 1991. Homoploid reticulate evolution in Helianthus (Asteraceae): evidence from ribosomal genes. Amer. J. Bot. 78: 1218-1237.

Rieseberg, L. H. \& Soltis, D. E. 1991. Phylogenetic consequences of cytoplasmic gene flow in plants. Evol. Trend. Pl. 5: 65-84.

Rieseberg, L. H. \& Wendel, J. F. 1993. Introgression and its consequences in plants. Pp. 70-109 in: Harrison, R. G. (ed.), Hybrid Zones and the Evolutionary Process. Oxford Univ. Press, New York.

Rieseberg, L. H., Whitton, J. \& Linder, C. R. 1996. Molecular marker incongruence in plant hybrid zones and phylogenetic trees. Acta Bot. Neerl. 45: 243-262.

Rivas-Martínez, S., Asensi, A., Molero, J. \& Valle, F. 1991. Endemismos vasculares de Andalucía. Rivasgodaya 6: 5-76.

Roelofs, D., van Velzen, J., Kuperus, P. \& Bachmann, K. 1997. Molecular evidence for an extinct parent of the tetraploid species Microseris acuminata and $M$. campestris (Asteraceae, Lactuceae). Molec. Ecol. 6: 641-649.

Rozen, S. \& Skaletsky, H. J. 2000. Primer3 on the WWW for general users and for biologist programmers. Pp. 365-386 in: Krawetz, S. \& Misener, S. (eds.), Bioinformatics Methods and Protocols: Methods in Molecular Biology. Humana Press, Totowa.

Sang, T., Crawford, D. J. \& Stuessy, T. F. 1995. Documentation of reticulate evolution in peonies (Paeonia) using internal transcribed spacer sequences of nuclear ribosomal DNA. Implications for biogeography and concerted evolution. Proc. Natl. Acad. Sci. U.S.A. 92: 6813-6817.

Sang, T., Crawford, D. J. \& Stuessy, T. F. 1997. Chloroplast DNA phylogeny, reticulate evolution, and biogeography of Paeonia (Paeoniaceae). Amer. J. Bot. 84: 1120-1136.

Swofford, D.L. 2001. PAUP*. Phylogenetic Analysis Using Parsimony (*and Other Methods). Version 4.010b. Sinauer Associates, Sunderland, Massachusetts.

Sytsma, K. J. 1990. DNA and morphology: inference of plant phylogeny. Trends Ecol. Evol. 5: 104-110.

Taberlet, P., Gielly, L., Pautou, G. \& Bouvet, J. 1991. Universal primers for amplification of three non-coding regions of chloroplast DNA. Pl. Molec. Biol. 17: 1105-1109.

Templeton, A. R., Crandall, K. A. \& Sing, C. F. 1992. A cladistic analysis of the phenotypic associations with haplotypes inferred from restriction endonuclease mapping and DNA sequence data. III. Cladogram estimation. Genetics 132: 619-633.

Vargas, P., McAllister, H. A., Morton, C., Jury, S. L. \& Wilkinson, M. J. 1999. Polyploid speciation in Hedera (Araliaceae): phylogenetic and biogeographic insights based on chromosome counts and ITS sequences. Pl. Syst. Evol. 219: 165-179.

Wendel, J. F., Schnabel, A. \& Seelanan, T. 1995. Bidirectional interlocus concerted evolution following allopolyploid speciation in cotton (Gossypium). Proc.
Natl. Acad. Sci. U.S.A. 92: 280-284.

Whittall, J., Liston, A., Gisler, S. \& Meinke, R. J. 2000. Detecting nucleotide additivity from direct sequences is a SNAP: an example from Sidalcea (Malvaceae). Pl. Biol. 2: 211-217.

Whittemore, A. T. \& Schaal, B. A. 1991. Interspecific gene flow in oaks. Proc. Natl. Acad. Sci. U.S.A. 88: 2540-2544.

Wichman, S. R., Wright, S. D., Cameron, E. K., Keeling, D. J. \& Gardner, R. C. 2002. Elevated genetic heterogeneity and Pleistocene climatic instability: inferences from nrDNA in New Zealand Coprosma (Rubiaceae). $J$. Biogeogr. 29: 943-954.

Wolfe, A. D. \& Elisens, W. J. 1995. Evidence of chloroplast capture and pollen-mediated gene flow in Penstemon sect. Peltanthera (Scrophulariaceae). Syst. Bot. 20: 395-412.

Yonemori, K., Honsho, C., Kanzaki, S., Eiadthong, W. \& Sugiura, A. 2002. Phylogenetic relationships of Mangifera species revealed by ITS sequences of nuclear ribosomal DNA and a possibility of their hybrid origin. $P l$. Syst. Evol. 231: 59-75.

Zimmer, E. A., Martin, S. L., Beverley, S. M., Kan, Y. W. \& Wilson, A. C. 1980. Rapid duplication and loss of genes coding for the alpha-chains of hemoglobin. Proc. Natl. Acad. Sci. U.S.A. 77: 2158-2162. 
Appendix. Collection data from material of Phlomis sampled for ITS and chloroplast markers.

Taxon: Accession, Locality (Specimen voucher), GeneBank accession number (ITS, trnH-psbA, trnT-trnL, atpB-rbcL).

P. lychnitis: 1/2, Cádiz: Grazalema, Cortijo de los Álamos (LY3-54/LY3-57), AY792771/AY792772, AY792624/AY792625, AY792673/AY792674, AY792722/AY792723; 3/4, Málaga: Casarabonela, Sierra Prieta (LY10-1/LY10-2), AY792773/AY792774, AY792626/AY792627, AY792675/AY792676, AY792724/AY792725; 5/6, Granada: Arenas del Rey, Los Bermejales (LY14-1/LY-14-2), AY792775/AY792776, AY792628/AY792629, AY792677/AY792678, AY792726/AY792727; 7/8, Granada: ascending towards Puerto de La Ragua (LY20-1/LY20-2), AY792777/AY792778, AY792630/AY792631, AY792679/AY792680, AY792728/AY792729; 9/10, Almería: Berja, Gádor mountain range (LY22-1/LY22-21), AY792779/AY792780, AY792632/AY792633, AY792681/AY792682, AY792730/AY792731; 11/12, Murcia: Umbría del Obispo, Sierra Seca (LY26-1/LY26-2), AY792781/AY792782, AY792634/AY792635, AY792683/AY792684, AY792732/AY792733; 13/14, Alicante: Crevillente, Crevillente mountain range (LY31-1/LY31-2), AY792783/AY792784, AY792636/AY792637, AY792685/AY792686, AY792734/AY792735; 15/16, Alicante: between Benimasot and Ballones (LY32-107/LY32-108), AY792785/AY792786, AY792638/AY792639, AY792687/AY792688, AY792736/AY792737; 17/18, Guadalajara: Tamajón, Nuestra Sra. de los Enebrales hermitage (LY41-1/LY41-2), AY792787/AY792788, AY792640/AY792641, AY792689/AY792690, AY792738/AY792739; 19, La Rioja: Dehesa de Ansejo. (MA-438426), AY792789, AY792642, AY792691, AY792740; 20, Valladolid: Bercero (MA-625727), AY792790, AY792643, AY792692, AY792741; 21, Badajoz: Fuenlabrada de los Montes (MA-564954), AY792791, AY792644, AY792693, AY792742; 22, Huesca: Graus (MA-530252), AY792792, AY792645, AY792694, AY792743; 23, Tarragona: Río Senia (MA-626509), AY792793, AY792646, AY792695, AY792744. P. crinita subsp. malacitana: 24/25, Cádiz: Grazalema, Puerto de las Palomas (MA2-50/MA2-53), AY792794/AY792795, AY792647/AY792648, AY792696/AY792697, AY792745/AY792746; 26/27, Málaga: Montejaque, Juan Diego mountain range, 1100 m. (MA6-1/MA6-2), AY792796/AY792797, AY792649/AY792650, AY792698/AY792699, AY792747/AY792748; 28/29, Málaga: Ronda, Sierra de las Nieves, Puerto de los Pilones (MA9-1/MA9-2), AY792798/AY792799, AY792651/AY792652, AY792700/AY792701, AY792749/AY792750; 30/31, Granada: Alhama de Granada, Almijara mountain range (MA12-1/MA12-3), AY792800/AY792801, AY792653/AY792654, AY792702/AY792703, AY792751/AY792752; 32/33, Granada: Arenas del Rey, Los Bermejales (MA14-1/MA14G), AY792802/AY792803, AY792655/AY792656, AY792704/AY792705, AY792753/AY792754; 34/35, Granada: Sierra Nevada, Puerto de la Ragua (MA19-1/MA19-5), AY792804/AY792805, AY792657/AY792658, AY792706/AY792707, AY792755/AY792756; 36/37, Almería: Berja, Gádor mountain range, $1600 \mathrm{~m}$ (MA22-8/MA22-39), AY792806/AY792807, AY792659/AY792660, AY792708/ AY792709, AY792757/AY792758. P. crinita subsp. crinita: 38/39, Albacete: Elche de la Sierra, Gallego (CR28-45/CR28-46), AY792808/AY792809, AY792661/AY792662, AY792710/AY792711, AY792759/AY792760; 40/41, Alicante: Crevillente, Crevillente mountain range (CR31-1/CR31-2), AY792810/AY792811, AY792663/AY792664, AY792712/AY792713, AY792761/AY792762; 42/43, Valencia: between Quesa and Navarrés (CR38-1/CR38-2), AY792812/AY792813, AY792665/AY792666, AY792714/AY792715, AY792763/AY792764; 44/45, Valencia: between Barix and Pinet (CR39-210/CR39-212), AY792814/AY792815, AY792667/AY792668, AY792716/AY792717, AY792765/AY792766. P. crinita subsp. mauritanica: 46, Morocco: Mid Atlas, Beni-Mellal. Ascending towards Jbel Tassemit (MOR-1), AY792816, AY792669, AY792718, AY792767; 47, Morocco: Mid Atlas, Ouarzazate, Tiki-N-Taghatine (MA434825), AY792817, AY792670, AY792719, AY792768; 48, Morocco: High Atlas, near Aït Mehammed (MA-625151), AY792818, AY792671, AY792720, AY792769. P. purpurea: 49, Cádiz: Zahara de la Sierra (PUR-1), AY792819, AY792672, AY792721, AY792770. P. Xmargaritae: 50/51, Cádiz: Zahara de la Sierra. Sierra Margarita (XMAR-1/XMAR-2), AY792820/AY792821, -/-, -/-, -/-. 